\title{
Sinorhizobium meliloti Requires a Cobalamin-Dependent Ribonucleotide Reductase for Symbiosis With Its Plant Host
}

\author{
Michiko E. Taga and Graham C. Walker \\ Department of Biology, Massachusetts Institute of Technology, 77 Massachusetts Avenue, Cambridge, MA 02139, U.S.A.
}

Submitted 2 July 2010. Accepted 2 August 2010.

\begin{abstract}
Vitamin $B_{12}$ (cobalamin) is a critical cofactor for animals and protists, yet its biosynthesis is limited to prokaryotes. We previously showed that the symbiotic nitrogen-fixing alphaproteobacterium Sinorhizobium meliloti requires cobalamin to establish a symbiotic relationship with its plant host, Medicago sativa (alfalfa). Here, the specific requirement for cobalamin in the $S$. meliloti-alfalfa symbiosis was investigated. Of the three known cobalamin-dependent enzymes in S. meliloti, the methylmalonyl CoA mutase (BhbA) does not affect symbiosis, whereas disruption of the metH gene encoding the cobalamin-dependent methionine synthase causes a significant defect in symbiosis. Expression of the cobalamin-independent methionine synthase MetE alleviates this symbiotic defect, indicating that the requirement for methionine synthesis does not reflect a need for the cobalamin-dependent enzyme. To investigate the function of the cobalamin-dependent ribonucleotide reductase (RNR) encoded by $n r d J, S$. meliloti was engineered to express an Escherichia coli cobalamin-independent (class Ia) RNR instead of $n r d J$. This strain is severely defective in symbiosis. Electron micrographs show that these cells can penetrate alfalfa nodules but are unable to differentiate into nitrogen-fixing bacteroids and, instead, are lysed in the plant cytoplasm. Flow cytometry analysis indicates that these bacteria are largely unable to undergo endoreduplication. These phenotypes may be due either to the inactivation of the class Ia RNR by reactive oxygen species, inadequate oxygen availability in the nodule, or both. These results show that the critical role of the cobalamin-dependent RNR for survival of $S$. meliloti in its plant host can account for the considerable resources that $S$. meliloti dedicates to cobalamin biosynthesis.
\end{abstract}

Vitamin $\mathrm{B}_{12}$ (cobalamin), one of the largest known nonpolymeric natural products, is a cofactor synthesized exclusively by prokaryotes that facilitates a variety of radical and methyl transfer reactions (Roth et al. 1996; Ryzhkova 2003). Cobalamin biosynthesis and utilization are distributed unevenly throughout nature. In most animals and protists, cobalamin is an essential cofactor that must be obtained from exogenous sources, whereas plants and fungi do not utilize cobalamin cofactors (Roth et al.

Current address for M. E. Taga: Department of Plant \& Microbial Biology, University of California, Berkeley, CA 94720, U.S.A.

Corresponding author: G. C. Walker; E-mail: gwalker@mit.edu

*The $\boldsymbol{e}$-Xtra logo stands for "electronic extra" and indicates that one supplementary figure is published online.
1996). The biosynthesis and utilization of cobalamin vary widely throughout the prokaryotic domains. The majority of sequenced prokaryotes do not possess a complete cobalamin biosynthesis pathway (Raux et al. 2000). Most cobalamin-dependent enzymes in prokaryotes function in metabolic processes for which equivalent cobalamin-independent pathways do not exist, such as methanogenesis, antibiotic synthesis, degradation of xenobiotic compounds, and utilization of glycerol, propanediol, ethanolamine, and various amino acids as sources for either carbon, nitrogen, or both (Ryzhkova 2003). In contrast, some bacteria such as Sinorhizobium meliloti use cobalamin cofactors for processes for which cobalamin-independent pathways also exist (Buckel et al. 2005; Rodionov et al. 2003; Roth et al. 1996; Ryzhkova 2003).

$S$. meliloti is one of many bacteria capable of synthesizing cobalamin de novo through an oxygen-dependent pathway (Campbell et al. 2006; Evans and Kliewer 1964). In S. meliloti, cobalamin functions as a cofactor for three enzymes, all of which have metabolically equivalent, cobalamin-independent counterparts in other organisms. One cobalamin-dependent enzyme in $S$. meliloti, methionine synthase (MetH), catalyzes the final step in methionine biosynthesis (Matthews 1999; Sato et al. 1974). Nearly all genera in the order Rhizobiales have the metH gene (Dehal et al. 2010), while the cobalamin-independent methionine synthase MetE, which is present in many organisms, is also present in $43 \%$ of the genera in the order Rhizobiales. Methylmalonyl CoA mutase (named BhbA in $S$. meliloti) is a cobalamin-dependent enzyme that catalyzes a step in the metabolism of branched-chain amino acids (Banerjee and Chowdhury 1999; Charles and Aneja 1999). Organisms that do not require cobalamin utilize the parallel, cobalamin-independent methylcitrate or acryloyl-CoA pathways (Buckel et al. 2005). S. meliloti also utilizes cobalamin for its class II ribonucleotide reductase (RNR) (Cowles and Evans 1968; Fontecave 1998). RNR catalyze the synthesis of deoxynucleotides (dNDP or dNTP) from ribonucleotides (NDP or NTP), which is the rate-limiting step in DNA synthesis (Kolberg et al. 2004). Most organisms utilize a cobalaminindependent (classes I or III) RNR, and over half of sequenced bacteria possess more than one RNR class (Lundin et al. 2009). It is possible that $S$. meliloti possesses one or more additional unknown classes of cobalamin-dependent enzymes.

Given the existence and abundance of these cobalamin-independent pathways, it seems remarkable that many bacteria have retained the ability to synthesize cobalamin, a process that requires the activity of approximately 30 genes that comprise 1 to $7 \%$ of a bacterial genome (McCutcheon et al. 2009; Roth et al. 1996). Characterization of a bluB mutant of $S$. meliloti, which led to the discovery of the enzyme responsible 
for the synthesis of the lower ligand of cobalamin, demonstrated that cobalamin is essential for $S$. meliloti symbiosis with Medicago sativa (alfalfa) but did not specify which cobalamin-dependent enzyme or enzymes contributed to the cobalamin requirement during symbiosis (Campbell et al. 2006; Taga et al. 2007). One hypothesis that could explain why $S$. meliloti synthesizes cobalamin for enzymes for which cobalamin-independent counterparts exist in closely related bacteria is that cobalamin-dependent enzymes provide an advantage for survival in the plant host. For example, both MetE and class Ia RNR are sensitive to reactive oxygen species (ROS) or reactive nitrogen species (RNS) or both, and $S$. meliloti is exposed to ROS and RNS when infecting the plant (Baudouin et al. 2006; Fontecave 1998; Hondorp and Matthews 2004; Rubio et al. 2004; Santos et al. 2000).

$S$. meliloti is a gram-negative alphaproteobacterium that exists either as a free-living member of the rhizosphere or as an intracellular nitrogen-fixing symbiont of legumes of the genera Medicago, Trigonella, and Melilotus (Gibson et al. 2008). In this mutualistic relationship, bacteria establish long-term residence within the cytoplasm of plant cells in specialized organs called nodules, in which they convert atmospheric nitrogen to ammonia, a process known as nitrogen fixation (Gibson et al. 2008; Jones et al. 2007). Bacteria initially enter the plant root via an infection thread, a plant-derived tubule formed within the root hair (Gage and Margolin 2000 ). The bacteria replicate in the infection thread and, subsequently, are internalized by plant cells of the nodule primordium by endocytosis (Gage 2002; Jones et al. 2007). Within the plant cytoplasm, bacteria develop into nondividing but metabolically active bacteroids (Jones et al. 2007; Oke and Long 1999b). When actively dividing, the bacteria accumulate and store poly-3-hydroxybutyrate (PHB) in granules that are later mobilized as a carbon source during bacteroid development (Lodwig and Poole 2003). During both invasion and bacteroid development, $S$. meliloti is exposed to plant-derived ROS and RNS, which function in both pathogen resistance and signaling (Baudouin et al. 2006; Rubio et al. 2004; Santos et al. 2000). The nodule is a microaerobic environment in which much of the oxygen is sequestered by plant leghemoglobin to allow the oxygen-sensitive nitrogenase enzyme to function while sustaining the obligately aerobic metabolism of the bacteria (Miller et al. 1988; Witty et al. 1987). In indeterminate nodules, a component of the bacteroid differentiation program is the plant-controlled process of endoreduplication, in which both the plant and bacterial cells increase their genomic copy number in the absence of cell division (Maunoury et al. 2010; Paau and Cowles 1978a; Paau et al. 1979). In the host plant Medicago truncatula, a relative of alfalfa, an average of 24 copies of the $S$. meliloti genome per bacteroid cell are present (Mergaert et al. 2006). The precise genomic copy number of $S$. meliloti bacteroids in alfalfa nodules has not been determined.

To determine which cobalamin-dependent enzymes in $S$. meliloti contribute to the cobalamin requirement during symbiosis with alfalfa, we have tested the symbiotic phenotypes of individual mutants in cobalamin-dependent enzymes. In addition, we have engineered $S$. meliloti strains that express cobalamin-independent enzymes in place of their cobalamindependent counterparts to test whether cobalamin-dependent enzymes have properties that enable $S$. meliloti to survive within nodules. We find that expression of a cobalamin-independent class Ia RNR cannot support $S$. meliloti during intracellular infection of its plant host, indicating that the requirement for cobalamin in $S$. meliloti is due to the function of the class II RNR.

\section{RESULTS}

\section{Contribution of $S$. meliloti metH and $b h b A$ to symbiosis with alfalfa.}

Our previous work showed that $S$. meliloti requires cobalamin for symbiosis with alfalfa (Campbell et al. 2006). This requirement is presumably due to the essential activity of at least one of the three cobalamin-dependent enzymes during symbiosis. To determine the contribution of each of these enzymes to symbiosis with alfalfa, the function of each cobalamin-dependent enzyme was examined individually. Alfalfa seedlings were inoculated with $S$. meliloti $\mathrm{Rm} 1021$ derivatives harboring a transposon insertion in $b h b A$ or metH, the genes encoding methylmalonyl CoA mutase and methionine synthase, respectively (Campbell et al. 2006; Charles and Aneja 1999). Plants inoculated with the $b h b A:: \operatorname{Tn} 5$ strain exhibited a Fix ${ }^{+}$ phenotype (i.e., able to fix nitrogen), as the average height and

Table 2. Nitrogenase activity in alfalfa inoculated with Rm1021 derivatives

\begin{tabular}{lcc}
\hline Sinorhizobium meliloti strain & No. scored & Acetylene reduction $^{\text {a }}$ \\
\hline Rm $1021 /$ vector $^{\mathrm{b}}$ & 5 & $86 \pm 18$ \\
$m e t H:: \operatorname{Tn} 5$ & 12 & $14 \pm 8$ \\
$m e t H:: \operatorname{Tn} 5 / \mathrm{pmetE} E^{+}\left(\operatorname{SmMetE}^{+}\right)$ & 6 & $77 \pm 30$ \\
$\Delta n r d J / \mathrm{p} n r d J^{+}\left(\operatorname{SmNrdJ}^{+}\right)$ & 5 & $75 \pm 17$ \\
$\Delta n r d J / \mathrm{p} n r d A B^{+}\left(\operatorname{SmNrdAB}{ }^{+}\right)$ & 10 & $3 \pm 11$
\end{tabular}

a Acetylene reduction activity for whole plants is presented as the rate of ethylene formation as a percentage of the average rate in plants inoculated with Rm1021. Numbers represent mean and standard error.

${ }^{\mathrm{b}}$ In some cases, data compiled from multiple independent experiments are presented.

Table 1. Phenotype of alfalfa inoculated with Rm1021 derivatives ${ }^{\mathrm{a}}$

\begin{tabular}{|c|c|c|c|c|}
\hline Sinorhizobium meliloti strain & Number of plants scored & Plant height $(\mathbf{c m})^{b}$ & Total nodules per plant ${ }^{b}$ & Pink nodules per plant ${ }^{\mathrm{b}, \mathrm{c}}$ \\
\hline Uninoculated & 24 & $1.7 \pm 0.1$ & $0 \pm 0$ & $\mathrm{~N} / \mathrm{A}^{\mathrm{d}}$ \\
\hline Rm1021 & 57 & $10.4 \pm 0.5$ & $23 \pm 2$ & $87 \pm 2$ \\
\hline$b h b A:: \operatorname{Tn} 5$ & 12 & $11.0 \pm 0.6$ & $23 \pm 3$ & $84 \pm 3$ \\
\hline$m e t H:: \operatorname{Tn} 5$ & 57 & $2.8 \pm 0.3$ & $21 \pm 1$ & $5 \pm 2$ \\
\hline met $H:: \operatorname{Tn} 5 /$ vector & 52 & $2.8 \pm 0.4$ & $21 \pm 2$ & $8 \pm 3$ \\
\hline metH::Tn5/pmetE $E^{+}\left(\operatorname{SmMetE^{+})}\right.$ & 41 & $6.7 \pm 0.6$ & $20 \pm 1$ & $59 \pm 1$ \\
\hline Rm1021/vector & 37 & $9.5 \pm 0.6$ & $22 \pm 2$ & $85 \pm 3$ \\
\hline $\mathrm{Rm} 1021 / \mathrm{pmet} E^{+}$ & 22 & $10.2 \pm 0.7$ & $25 \pm 3$ & $84 \pm 3$ \\
\hline$\Delta n r d J / \mathrm{p} n r d J^{+}\left(S m \mathrm{NrdJ}^{+}\right)$ & 26 & $8.6 \pm 0.4$ & $27 \pm 2$ & $81 \pm 4$ \\
\hline$\Delta n r d J / \mathrm{p} n r d A B^{+}\left(\operatorname{SmNrd\mathrm {AB}^{+})}\right.$ & 44 & $2.3 \pm 0.1$ & $23 \pm 2$ & $1 \pm 1$ \\
\hline $\mathrm{Rm} 1021 / \mathrm{p} n r d J^{+}$ & 33 & $8.9 \pm 0.6$ & $21 \pm 2$ & $83 \pm 2$ \\
\hline $\mathrm{Rm} 1021 / \mathrm{p} n r d A B^{+}$ & 37 & $9.4 \pm 0.6$ & $19 \pm 1$ & $86 \pm 2$ \\
\hline
\end{tabular}

${ }^{a}$ Data compiled from multiple independent experiments are presented.

${ }^{\mathrm{b}}$ Numbers represent mean and standard error.

${ }^{\mathrm{c}}$ As a percentage of total nodules

${ }^{\mathrm{d}}$ Not applicable; no nodules were present. 
percent pink nodules of these plants were indistinguishable from plants inoculated with Rm1021 (Table 1). Thus, $b h b A$ is not required for symbiosis.

In contrast, plants inoculated with the $S$. meliloti metH::Tn5 mutant exhibited a $\mathrm{Fix}^{-}$phenotype (i.e., unable to fix nitrogen), as observed by their low average height and scarcity of pink nodules (Table 1). Free-living growth analysis confirmed that the metH::Tn5 mutant is a methionine auxotroph (Supplementary Fig. 1A). Therefore, it is likely that the Fix ${ }^{-}$phenotype is due to a lack of free methionine in the nodule. This result is in agreement with a previous study of methionine auxotrophs of S. meliloti Rmd201 (Abbas et al. 2002) but not strain 102F34, which can use glycine betaine as an alternative methionine source (Barra et al. 2006).

To test whether a cobalamin-independent methionine synthase could substitute for MetH during symbiosis in the Rm1021 strain background, a plasmid containing the Escherichia coli cobalamin-independent methionine synthase, metE (Chu et al. 1985), was expressed in a metH::Tn5 mutant. For simplicity, we will refer to this strain as $S m \mathrm{MetE}^{+}$. The E. coli metE gene is able to function in $S$. meliloti, as expression of metE suppresses the methionine auxotrophy of metH::Tn5. Furthermore, metE complements the Fix ${ }^{-}$phenotype of the metH::Tn5 mutant, as the average plant height, percent pink nodules, and nitrogenase activity are dramatically improved (Tables 1 and 2). The incomplete rescue of the plant height and number of pink nodules per plant and high variability in nitrogen fixation in $S m \mathrm{MetE}^{+}$is likely due to the 100 -fold slower turnover number of MetE compared with MetH (Gonzalez et al. 1992). This result demonstrates that $S$. meliloti Rm1021 must synthesize methionine in order to establish an effective symbiosis, but it is not necessary that the methionine synthase used for this purpose be cobalamin-dependent.

\section{The $E$. coli class Ia RNR functions \\ in free-living growth of $S$. meliloti but not in symbiosis.}

Next, we sought to test the function of the $S$. meliloti cobalamin-dependent (class II) RNR, encoded by $n r d J$, during symbiosis with alfalfa. The $n r d J$ gene is essential for DNA synthesis, as no other RNR exists in the S. meliloti genome. Therefore, we tested whether $S$. meliloti could function when $n r d J$ is substituted with genes encoding a class Ia (cobalamin-independent) RNR. The chromosomal $n r d J$ gene was deleted in the presence of a plasmid expressing $n r d A$ and $n r d B$ from E. coli, which together encode a class Ia RNR (Carlson et al. 1984). As a control, a class II RNR, nrdJ from Agrobacterium tumefaciens, was expressed in an $S$. meliloti $\Delta n r d J$ strain. Hereafter, these strains will be called $\mathrm{SmNrdAB}^{+}$and $\mathrm{SmNrdJ}^{+}$, respectively. Both strains are viable in the free-living state and are not impaired in cobalamin-dependent growth in minimal media. Furthermore, as expected, the class I RNR-specific inhibitor hydroxyurea (HU) inhibits the growth of $\mathrm{SmNrdAB}^{+}$(Elford 1968). Although the optical density at $600 \mathrm{~nm}$ continues to increase, treatment of $\mathrm{SmNrdAB}^{+}$with $\mathrm{HU}$ results in cell death as in the case of $E$. coli (Davies et al. 2009). In contrast, $\mathrm{SmNrdJ}^{+}$, like wild-type $S$. meliloti, is not affected by HU.

As expected, plants inoculated with $\mathrm{SmNrdJ}^{+}$have a phenotype indistinguishable from those inoculated with $\mathrm{Rm} 1021$ (Fig. 1A, B, D, and E; Tables 1 and 2). In contrast, SmNrdAB ${ }^{+}$ has a profound defect in symbiosis. This defect is apparent on a gross morphological level, as the plants are short with yellow leaves and the nodules, though occasionally elongated, are nearly all white (Fig. 1C and F). Like Rm1021 and SmNrdJ (Fig. $1 \mathrm{G}$ and $\mathrm{H}$ ), $\mathrm{SmNrdAB}^{+}$is competent for nodule invasion, as nodules of plants inoculated with gus-expressing bacteria show $\beta$-glucuronidase (GUS) activity throughout the nodule for both elongated (Fig. 1I) and small, round nodules (not shown). The average height of plants inoculated with $\mathrm{SmNrdAB}^{+}$is only slightly greater than uninoculated plants, and a pink nodule was rarely observed (Table 1). A low level of nitrogenase activity was detectable in some plants, indicating that few bacteria could successfully develop into bacteroids and fix nitrogen (Table 2). This defect in symbiosis was not caused by a lack of $n r d A$ or $n r d B$ expression in the plant, as both NrdA and NrdB proteins were detected in nodule extracts by Western blot (not shown). Moreover, the defect in symbiosis was likely not due to oxygen limitation in the nodule, as coexpression of $n r d D$ and $n r d G$, which encode the $E$. coli class III (anaerobic) RNR (Garriga et al. 1996), with $n r d A$ and $n r d B$ did not improve the symbiotic phenotype (not shown). The plasmids expressing $n r d J$ or $n r d A B$ did not affect free-living growth or symbiosis when expressed in $S$. meliloti containing wild-type $n r d J$ (Table 1). Together, these results demonstrate that the cobalamin-independent RNR NrdAB can support free-living growth of $S$. meliloti but does not function in symbiosis with alfalfa. Furthermore, the requirement for the class II RNR for symbiosis explains the dependence of $S$. meliloti on cobalamin biosynthesis.

\section{Bacteria isolated from nodules of plants inoculated with $\mathrm{SmNrdAB}{ }^{+}$ appear morphologically similar to bacteroids.}

In the normal development of the $S$. meliloti-alfalfa symbiosis, $S$. meliloti cells are released from infection threads into the plant cytoplasm following invasion of the nodule. The cells then undergo a series of physiological and morphological changes, including cell elongation and branching as they differentiate into mature, nitrogen-fixing bacteroids. $\mathrm{SmNrdAB}^{+}$ is apparently unable to complete this process, as its nitrogenfixing activity is very low despite the ability to invade the nodule (Table 2; Fig. 1I). To investigate the nature of this defect, bacterial cells isolated from nodules were examined by microscopy. As a control, we first visualized free-living Rm1021, $\mathrm{SmNrdJ}^{+}$, and SmNrdAB and observed no detectable difference in cell morphology or 4',6-diamidino-2-phenylindole (DAPI) staining pattern (Fig. 2A through C). To examine bacterial cells from nodules, nodules were crushed and the released bacteria were visualized by microscopy. Surprisingly few bacterial cells were isolated from nodules of plants inoculated with $\mathrm{SmNrdAB}^{+}$, considering that the level of bacterially expressed GUS appeared comparable to the level in nodules containing $\mathrm{Rm}_{1021}$ or $\mathrm{SmNrdJ}^{+}$(Fig. 1D through F). However, the few bacterial cells isolated from these nodules are morphologically indistinguishable from those isolated from Rm1021 and $\mathrm{SmNrdJ}^{+}$(Fig. 2D through F). The cells contain hallmarks of mature bacteroids, including their elongated, Y-shaped morphology and punctate DAPI staining. The low level of nitrogenase activity observed in plants inoculated with $\mathrm{SmNrdAB}^{+}$ (Table 2) could be explained by the presence of these very few bacteroids in the nodule. However, the normal GUS activity present throughout these nodules (Fig. 1I) does not reflect this reduction in bacterial cell number and, instead, could indicate that some cell lysis of $\mathrm{SmNrdAB}^{+}$occurs in the nodule.

\section{Endoreduplication is incomplete}

\section{in $S$. meliloti containing a class Ia RNR.}

Given that RNR are necessary for providing the dNTP substrates for DNA replication, we addressed the possibility that the defect in nitrogen fixation observed in plants inoculated with $\mathrm{SmNrdAB}^{+}$could be explained by incomplete endoreduplication. To analyze the DNA content in the bacterial cells quantitatively, cells were fixed with ethanol, were treated with the nucleic acid-binding dye Sytox Green, and were analyzed by flow cytometry. As a control, the DNA content of free-liv- 
ing bacteria was examined. As observed previously (Mergaert et al. 2006), the DNA content in free-living bacteria shows two distinct peaks corresponding to one and two copies of the genome (1n and 2n) (Fig. 3, vertical dotted lines), and no difference was observed among the three strains (Fig. 3A through C). The size and shape distributions show a homogeneous population and are nearly identical among the three strains (Fig. 3D through F).

Flow cytometry analysis of bacterial cells isolated from alfalfa nodules inoculated with Rm1021 shows a broad dominant peak with DNA content centered around $3 \mathrm{n}$ and a minor peak at $1 \mathrm{n}$ (Fig. 3G). The $\mathrm{SmNrdJ}^{+}$nodule extracts show a similar pattern (Fig. $3 \mathrm{H}$ ). In contrast, the distribution of DNA content of $\mathrm{SmNrdAB}^{+}$cells extracted from nodules shows a dominant peak at $1 \mathrm{n}$ and a broad peak centered at $2 \mathrm{n}$ (Fig. 3I).
The distribution of DNA content in Rm1021 nodule extracts is more similar to previous flow microfluorometry analyses of $S$. meliloti extracted from alfalfa nodules (Paau and Cowles 1978b; Paau et al. 1979) than flow cytometry analysis of purified bacteroids extracted from nodules of $M$. truncatula, a relative of alfalfa (Mergaert et al. 2006). This difference can be explained by either a difference between alfalfa and $M$. truncatula, a difference in the bacteroid purification method, or both.

The size and shape distributions of cells extracted from nodules containing $\mathrm{Rm} 1021$ or $\mathrm{SmNrdJ}^{+}$(Fig. 3J and K) are distinct from those of free-living bacteria (Fig. 3D and E) and reflect the differences in size and morphology between freeliving bacteria and bacteroids. The DNA content and size and shape distributions of these strains differ significantly from $\mathrm{SmNrdAB}^{+}$(Fig. 3I and L). The $\mathrm{SmNrdAB}^{+}$nodule extracts
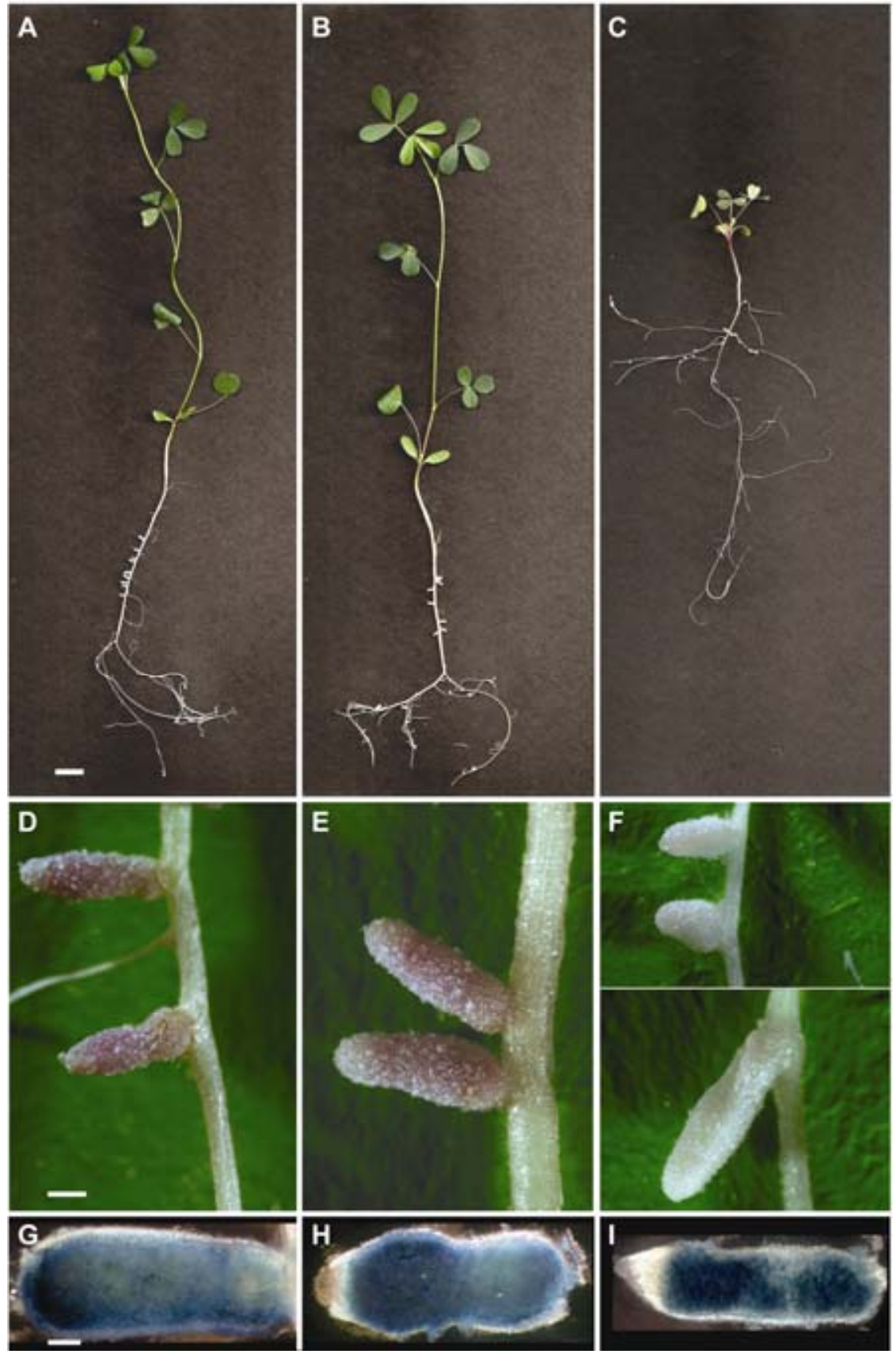

Fig. 1. Phenotype of alfalfa inoculated with Sinorhizobium meliloti expressing different ribonucleotide reductases (RNR). A through C, Whole plants, D through $\mathbf{F}$, nodules, and $\mathbf{G}$ through $\mathbf{I}$, nodules stained with gus-expressing S. meliloti are shown for alfalfa inoculated with Rm1021 (A, D, G), SmNrdJ ${ }^{+}$(B, E, H), and $\operatorname{SmNrdAB}^{+}$(C, F, I). Scale bars represent $5 \mathrm{~mm}$ (A through C), $0.5 \mathrm{~mm}$ (D through F), and $0.25 \mathrm{~mm}$ (G through I). 
contain a mixture of two populations of equivalent cell number with distinct size and shape distributions (Fig. 3L). The DNA content of one population (Fig. 3L, group a) is similar to freeliving stationary-phase cells, suggesting that these cells have not initiated the endoreduplication process (Fig. 3M, group a compared with that in A through C). The other population (Fig. 3L, group b) largely consists of unstained particles, possibly including cells lacking DNA, as there are relatively few cells with significant DNA content (Fig. 3M, group b). Some cells in this population contain more than 2n DNA content, suggesting that endoreduplication may occur in a minority population (Fig. 3M, group b compared with that in G). The low nitrogenase activity detected in plants inoculated with $\mathrm{SmNrdAB}^{+}$ (Table 2) could be due to this population.

\section{SmNrdAB ${ }^{+}$bacteria are unable to persist in the nodule.}

The scarcity of bacterial cells extracted from nodules of alfalfa inoculated with $\mathrm{SmNrdAB}^{+}$and their defect in endoreduplication prompted a closer examination of these nodules by transmission electron microscopy. In nodules containing $\mathrm{SmNrdJ}^{+}$, which are indistinguishable from those containing Rm1021 (not shown), the plant cells are filled with bacteroids (Fig. 4A), whereas those inoculated with $\mathrm{SmNrdAB}^{+}$contain infection threads but bacteroids are not visible in the plant cytoplasm (Fig. 4B). Consistent with a lack of nitrogen-fixing bacteroids, numerous amyloplasts are present in the nodule cells of plants inoculated with $\mathrm{SmNrdAB}^{+}$(Fig. 4B). Unlike in infection threads containing $\mathrm{SmNrdJ}^{+}$(Fig. 4C), some cells with morphological irregularities are present in infection threads containing $\mathrm{SmNrdAB}^{+}$(Fig. 4D). Moreover, $\mathrm{SmNrdJ}^{+}$ cells are capable of differentiating into mature bacteroids (Fig. 4C), while in nodules containing $\mathrm{SmNrdAB}^{+}$, bacterial cells are initially released into the plant cytoplasm but do not differentiate into bacteroids (Fig. 4D). Instead, membranes that appear to have been derived from bacteria accumulate in the plant cytoplasm of nodules inoculated with $\mathrm{SmNrdAB}^{+}$(Fig. 4D through F). Many of these structures appear to contain PHB granules, suggesting a bacterial origin (Fig. 4F). The presence of bacteria in infection threads containing $\mathrm{SmNrdAB}^{+}$demonstrates that this strain is competent for replication in the infection thread, albeit with slightly altered cell morphology. These cells appear to be killed shortly after release into the cytoplasm, as they have not depleted their PHB supply. The abundance of these bacterial cell remnants could explain the normal level of GUS activity we observed, as the GUS protein is stable enough to persist in nodules after the cells have been damaged.

\section{$\mathrm{SmNrdAB}^{+}$cells in nodules are distinct from free-living $\mathrm{SmNrdAB}{ }^{+}$treated with $\mathrm{HU}$.}

The phenotype of $\mathrm{SmNrdAB}^{+}$that we observed by electron microscopy suggests that inhibition of RNR activity, and thus reduction in dNTP pools, in the nodule environment results in the accumulation of empty or PHB-containing membranes in the plant cytoplasm. To understand the physiological basis of this phenotype, we tested whether inhibition of RNR activity by treatment with $\mathrm{HU}$ in free-living $\mathrm{SmNrdAB}^{+}$could mimic the phenotype of $\mathrm{SmNrdAB}^{+}$within the nodule. The cellular morphology of $\mathrm{SmNrdAB}^{+}$following growth with $\mathrm{HU}$ for $6 \mathrm{~h}$ appears similar to that of cells isolated from nodules, as the cells become elongated and branched (Fig. 5A, upper panel). However, unlike cells extracted from nodules (Fig. 2D through F), the DNA in HU-treated cells is diffusely distributed in most cells (Fig. 5A, lower panel). HU treatment causes loss of viability in $99 \%$ of cells without a corresponding loss in culture turbidity, indicating that, unlike in nodules, extensive cell lysis does not occur. Flow cytometry analysis of the DNA in
$\mathrm{SmNrdAB}^{+}$treated with $\mathrm{HU}$ for $20 \mathrm{~h}$ shows that most cells fall within a broad distribution centered at a DNA content slightly lower than 2n (Fig. 5B). These cells can be partitioned into two populations with distinct size and shape distributions (Fig. 5C). The DNA content in one of these populations (Fig. 5C and D, group a) is broadly distributed, with the majority containing incomplete genomic content (less than 1n). The other population (Fig. 5C and D, group b) contains cells whose DNA content is centered near $2 \mathrm{n}$, but this distribution is broader than that of untreated cells (Fig. 5D, group b, compared with that in Fig. 3A through C). Although HU-treated cells appear morphologically similar to bacteroids, their DNA content and their size and shape distributions are distinct from both untreated free-living bacteria and bacteria extracted from nodules (Fig. 5C and D compared with Fig. 3). Together, these results demonstrate that inhibition of RNR activity in free-living $S$. meliloti results in physiological changes distinct from those resulting from the loss of RNR activity in the nodule.

\section{SmNrdAB ${ }^{+}$cells are sensitive to $\mathrm{ROS}$.}

Our observation that the class II RNR (NrdJ) can function in the plant while the class Ia RNR (NrdAB) cannot suggests either that the NrdAB enzyme is inhibited in the plant or that a factor required for its activity is absent from the plant. Although classes I and II RNR both catalyze the synthesis of deoxynucleotides, the catalytic mechanisms differ between the two classes. Specifically, the stable tyrosyl radical in class Ia RNR, which is used to generate a transient cysteinyl radical, can be quenched by HU or ROS (Fontecave and
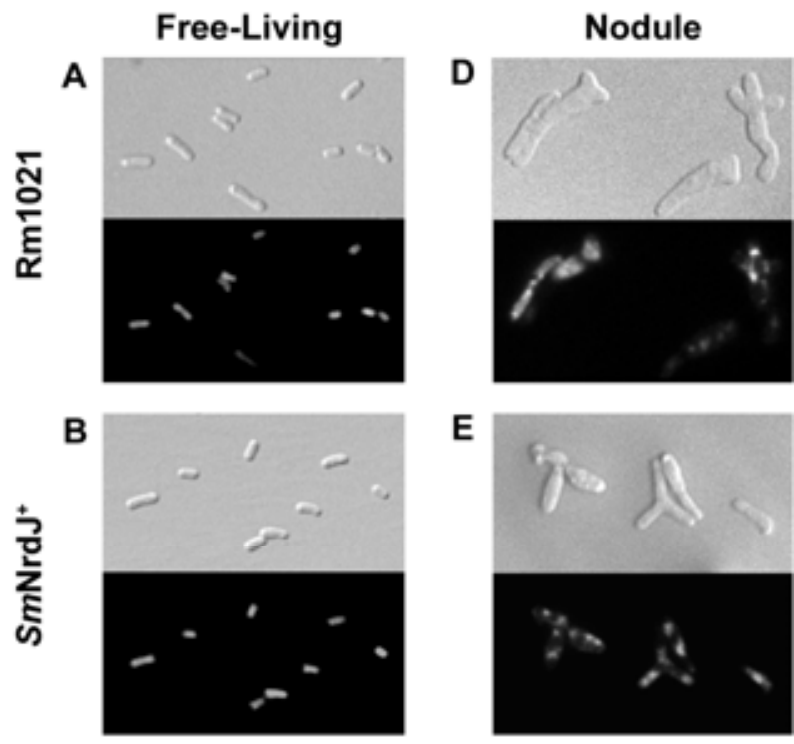

E
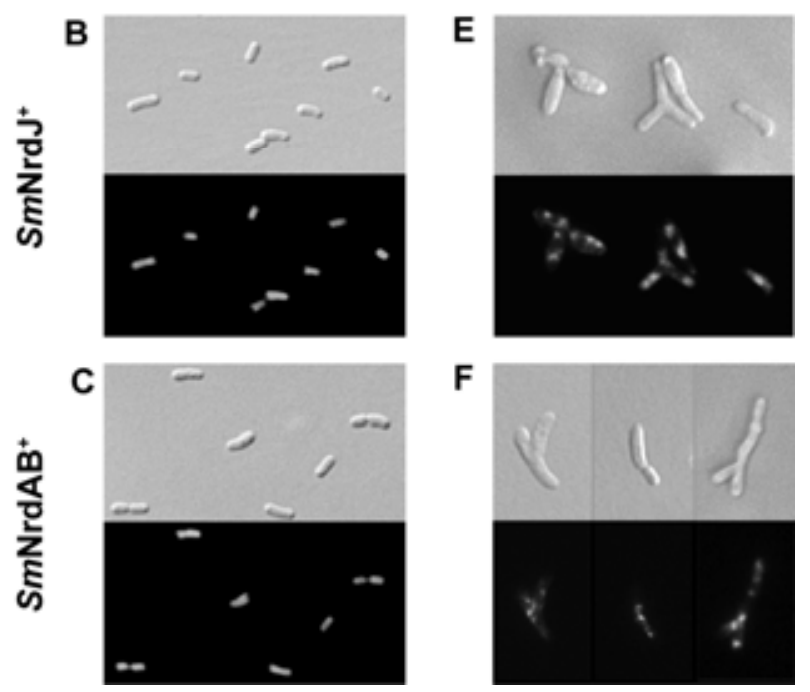

$\mathbf{F}$

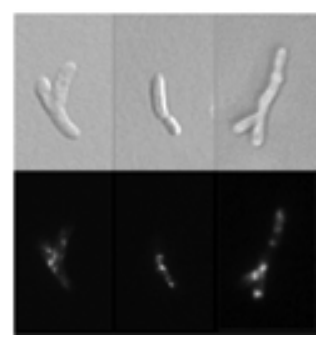

Fig. 2. Cellular morphology and DNA distribution of free-living bacteria and alfalfa nodule extracts. 4',6-Diamidino-2-phenylindole-stained bacteria visualized by Nomarski (upper panels) and fluorescence microscopy (lower panels) are shown for $\mathbf{A}$ and $\mathbf{D}, \mathrm{Rm} 1021, \mathbf{B}$ and $\mathbf{E}, \operatorname{SmNrdJ}{ }^{+}$, and $\mathbf{C}$ and $\mathbf{F}, S m \mathrm{NrdAB}^{+}$. Free-living bacteria grown to exponential phase (A through $\mathrm{C}$ ) and bacterial cells extracted from nodules (D through $\mathrm{F}$ ) are shown. 
Gerez 2002), whereas class II RNR use adenosylcobalamin to generate a transient cysteinyl radical and, hence, are not sensitive to HU or ROS. S. meliloti encounters ROS produced by the plant during infection, and therefore inactivation of the class Ia RNR by ROS could explain the inability of $\mathrm{SmNrdAB}^{+}$to survive in the plant. To determine whether $\mathrm{SmNrdAB}^{+}$is indeed sensitive to ROS, its survival in the presence of ROS was tested. Compared with strains expressing $n r d J, \mathrm{SmNrdAB}^{+}$is sensitive to hydrogen peroxide and the ROS-generating compounds menadione and cumene hydroperoxide, as significantly fewer colonies grew on plates containing these agents (Fig. 6). This result suggests that the sensitivity of $\mathrm{SmNrdAB}^{+}$to ROS could contribute to its failure to survive in the plant.

\section{DISCUSSION}

In a previous study, we found that the biosynthesis of cobalamin is necessary for $S$. meliloti to form a productive symbiotic relationship with alfalfa. The primary objective of the present study was to determine which cobalamin-dependent enzyme or enzymes in $S$. meliloti is necessary during symbiosis with alfalfa. Here, we find that a cobalamin-dependent (class II) RNR is specifically required for symbiosis, whereas the cobalamin-dependent methylmalonyl-CoA mutase (BhbA) is not required at all and $S$. meliloti can function in the nodule with either a cobalamin-dependent or cobalamin-independent methionine synthase. Substitution of NrdJ with the E. coli cobalamin-independent (class Ia) RNR results in an unusual symbiotic defect characterized by irregular cell morphology in infection threads and cell lysis in the nodule. Thus, the class Ia RNR apparently loses its enzyme activity in the infection thread or in the plant cytoplasm or both.

This study also raises a broader question regarding why certain bacteria such as $S$. meliloti use cobalamin exclusively for metabolic functions for which other organisms do not require cobalamin. Given that cobalamin-independent counterparts of MetH and NrdJ exist in bacteria closely related to S. meliloti (Dehal et al. 2010; Lundin et al. 2009), it might seem more evolutionarily favorable for $S$. meliloti not to have retained its requirement for cobalamin biosynthesis and, instead, to have utilized only cobalamin-independent enzymes. However, the inability of a cobalamin-independent RNR to function in $S$. meliloti during symbiosis that we observe here could explain why $S$. meliloti makes the substantial genetic investment necessary to synthesize cobalamin when metabolically equivalent cobalamin-independent processes are available.

The phenotype of $\mathrm{SmNrdAB}^{+}$in the nodule, in which empty or PHB-containing bacterial cell membranes accumulate in the plant cytoplasm, is distinct from previously observed phenotypes of $S$. meliloti lacking the ability to fix nitrogen, detoxify ROS, or form a normal outer membrane (Campbell et al. 2002;
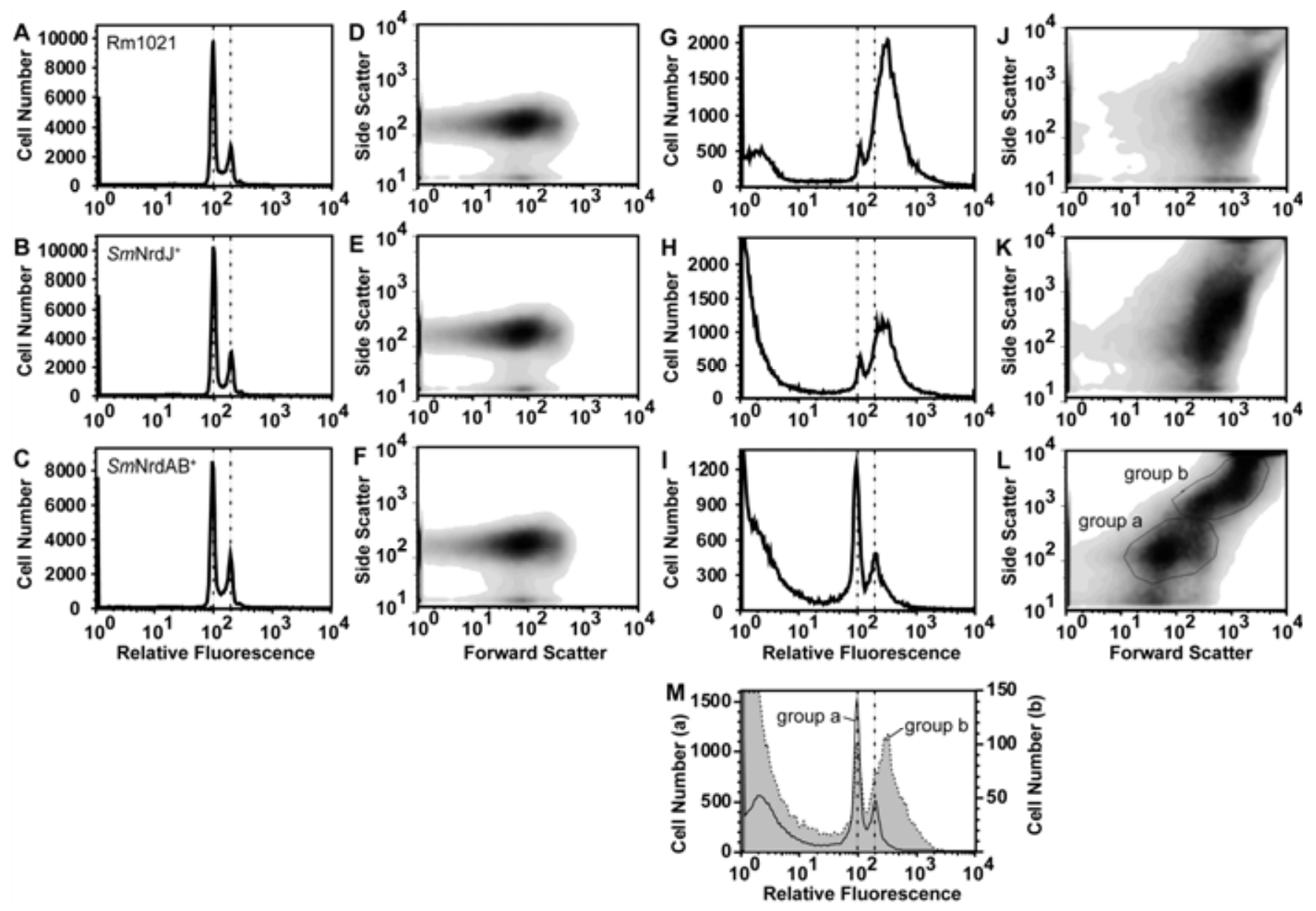

Fig. 3. DNA content of free-living bacteria and alfalfa nodule extracts. A through F, Flow cytometry of Sytox Green-stained stationary-phase free-living bacteria and $\mathbf{G}$ through $\mathbf{L}$, bacterial cells isolated from nodules are shown. Histogram plots (A through $\mathrm{C}$ and $\mathrm{G}$ through $\mathrm{I}$ ) and corresponding density plots showing the relative size and shape distribution (D through F and J through L) are presented for Rm1021 (A, D, G, and J), SmNrdJ ${ }^{+}$(B, E, H, and K), and $S m \mathrm{NrdAB}^{+}$(C, F, I, and L). Genomic DNA content corresponding to $1 \mathrm{n}$ and $2 \mathrm{n}$ are marked with vertical dotted lines. The presence of objects with little or no Sytox Green staining ( $\mathrm{G}$ through $\mathrm{I}$ ) is partially due to degradation of the samples. M, Histogram plots of the two populations indicated in L (group a, solid line; group b, shaded). Note the 10 -fold difference in the scale of the $y$ axis. 

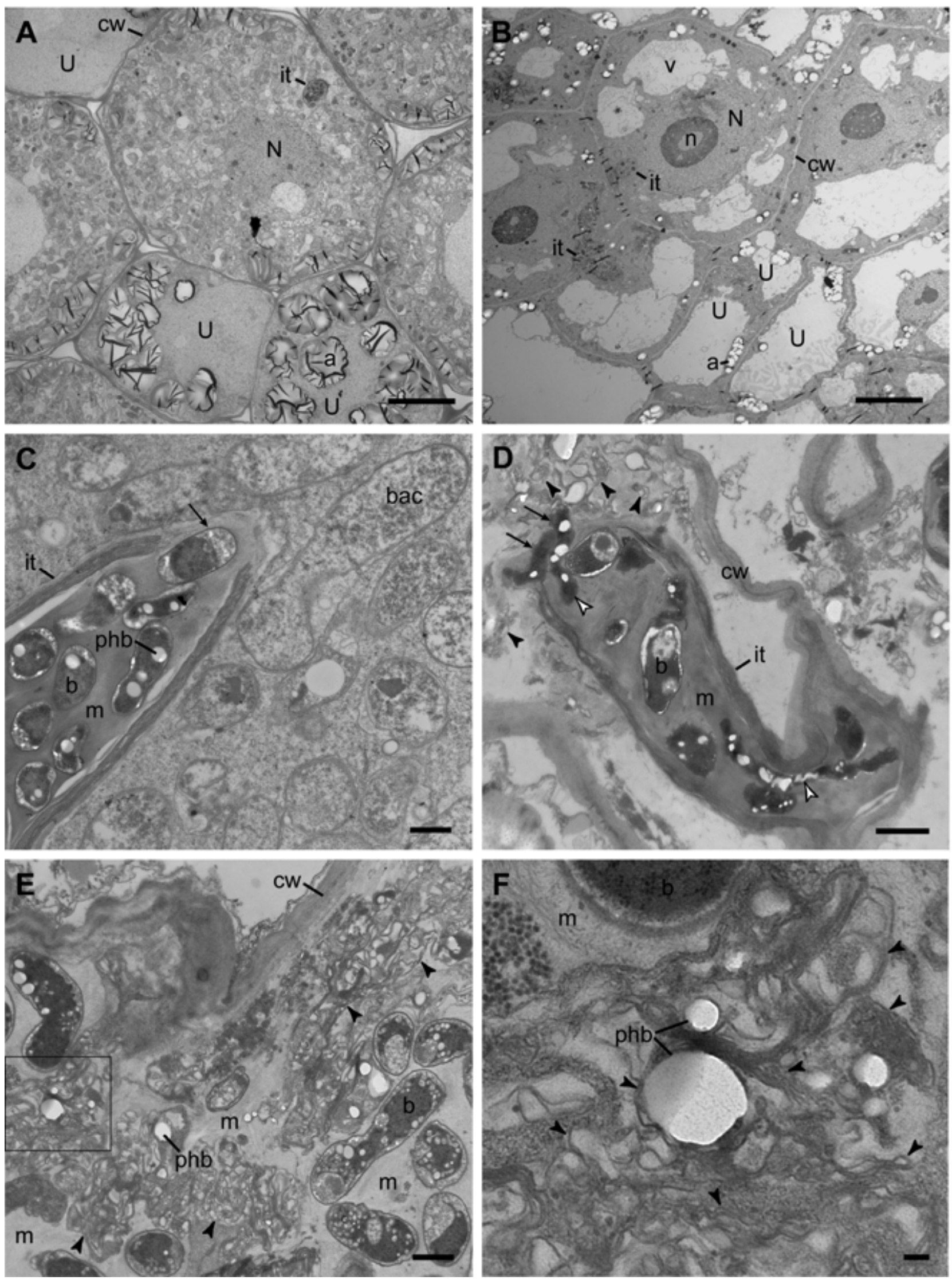

Fig. 4. Transmission electron micrographs of sectioned nodules. A and $\mathbf{C}$, Micrographs of alfalfa nodules inoculated with $\operatorname{SmNrdJ^{+}}$ or $\mathbf{B}$ and $\mathbf{D}$ through $\mathbf{F}$, $\operatorname{SmNrdAB}{ }^{+}$. F represents a higher magnification image of the boxed area in E. Scale bars represent $10 \mu \mathrm{m}(\mathrm{A}$ and B), $1 \mu \mathrm{m}(\mathrm{C}$ through E), and $0.1 \mu \mathrm{m}(\mathrm{F})$. $S m N_{r d A B}+$ micrographs shown in B, D, and $\mathrm{E}$ are from three different nodules fixed in two independent experiments. $\mathrm{Cw}=$ plant cell wall, $\mathrm{U}=$ uninfected cell, it $=$ infection thread, $\mathrm{v}=$ vacuole, $\mathrm{a}=$ amyloplast, $\mathrm{N}=$ nucleus, $\mathrm{n}=$ nucleolus, $\mathrm{b}=$ undifferentiated bacterium, bac $=$ bacteroid, $\mathrm{m}=$ infection thread matrix, $\mathrm{phb}=$ polyhydroxybutyrate granule. Arrows in $\mathrm{C}$ and $\mathrm{D}$ indicate bacteria exiting infection thread; white arrowheads in $\mathrm{D}$ indicate elongated bacteria in infection thread; black arrowheads in D through $\mathrm{F}$ indicate membrane fragments possibly derived from lysed bacteria. 
Glazebrook et al. 1993; Hirsch et al. 1983; Jamet et al. 2003). The morphology of $\mathrm{SmNrdAB}^{+}$in alfalfa nodules appears similar to wild-type $S$. meliloti in nodules of an $M$. truncatula dnfl mutant; in both cases, cells released from infection threads do not differentiate into mature bacteroids, although the dnfl mutant does not induce bacterial cell lysis (Wang et al. 2010). We assume that the phenotype of $\mathrm{SmNrdAB}^{+}$is entirely due to inactivation of the RNR within the plant, as the only genetic difference between $\mathrm{SmNrdAB}^{+}$and $\mathrm{SmNrdJ}^{+}$is the RNR. Our observation that the phenotype of $\mathrm{SmNrdAB}^{+}$in the nodule is distinct from free-living $\mathrm{SmNrdAB}^{+}$treated with HU suggests that factors in the plant cytoplasm that induce bacterial endoreduplication, alteration of the bacterial cell envelope, cell enlargement, or other physiological changes associated with bacteroid differentiation influence whether cells lyse in response to RNR inactivation.

The difference between the phenotypes of $S$. meliloti expressing a class Ia versus a class II RNR is presumably a result of an important difference in the catalytic properties of these two RNR classes. The known differences between these enzymes are the requirement for adenosylcobalamin by the class II RNR and the requirements for iron, oxygen, and the formation of a tyrosyl radical in the class Ia RNR. Thus, the inability of the class Ia RNR to function in the plant is likely due to an insufficient supply of iron or oxygen or a deficiency in the formation or stability of the tyrosyl radical. Iron limitation is not likely to be the source of the symbiotic defect of $\mathrm{SmNrdAB}^{+}$, because the plant growth medium contains sufficient iron and wild-type $S$. meliloti can survive in nodules even in the presence of an iron chelator (Battistoni et al. 2002). Moreover, previous transcriptomics and proteomics studies of $S$. meliloti in $M$. truncatula and alfalfa nodules had indicated that an iron transporter is induced in the nodule, which had appeared to suggest that iron is limiting; however, this transporter was later shown to be specific to manganese (Ampe et al. 2003; Davies and Walker 2007; Djordjevic 2004). Oxygen limitation is a more plausible explanation for the $\mathrm{SmNrdAB}^{+}$phenotype, as the nodule environment is microaerobic. Although we observed that coexpression of the $E$. coli class Ia and III (oxygen-sensitive) RNR in S. meliloti did not result in symbiotic proficiency, it is possible that the class III RNR does not function in the nodule environment. An additional explanation for the inability of NrdAB to function in the nodule is that the stable tyrosyl radical of a class Ia RNR is inactivated by ROS during infection, subsequently leading to DNA damage and eventually cell death. This is based on our observation that $\mathrm{SmNrdAB}^{+}$is sensitive to ROS coupled with previous evidence that plant-derived ROS are abundant during infection (Baudouin et al. 2006; Rubio et al. 2004; Santos et al. 2000). Regardless of the mode of inactivation of NrdAB in S. meliloti, it is important to recognize that the plant host also relies on a class Ia RNR for cell division and endoreduplication and this enzyme is functional in the same environment in which the bacterial enzyme is not (Fontecave 1998).
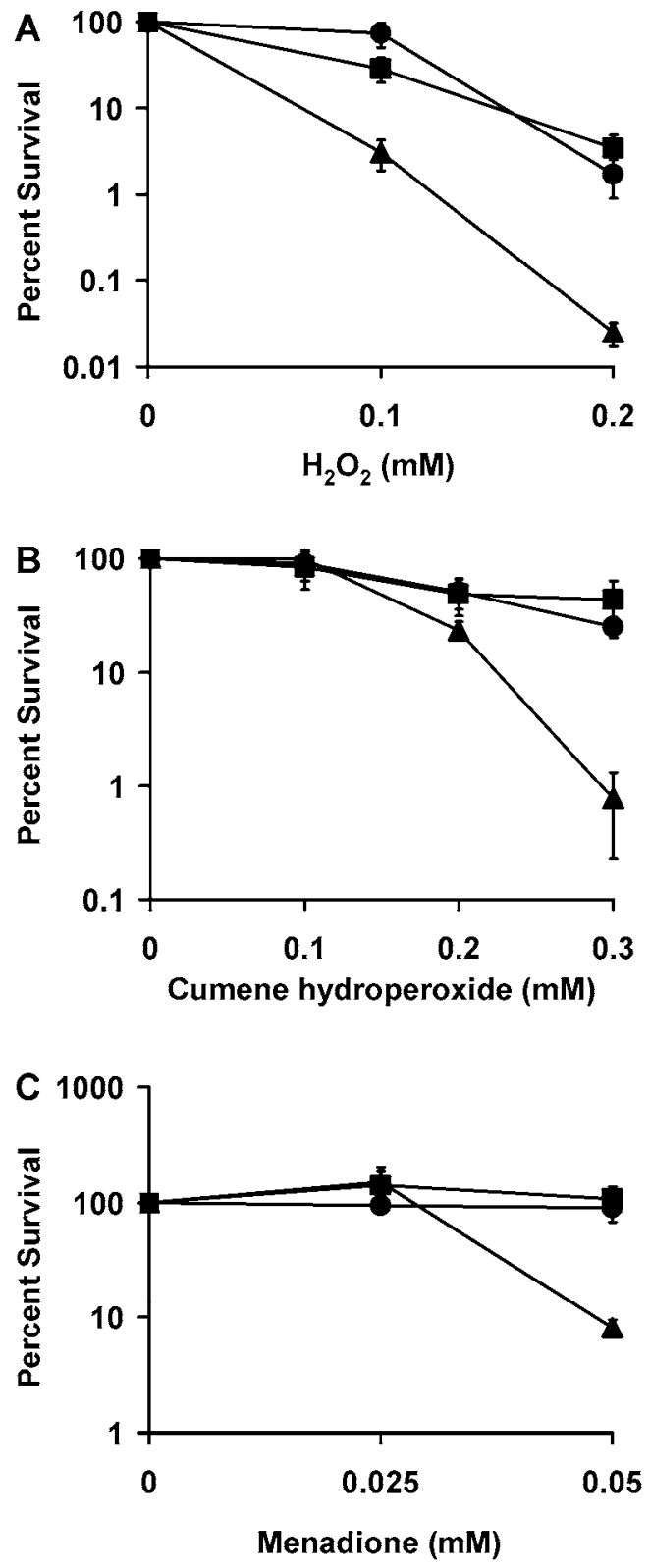

Fig. 6. Heterologous expression of Escherichia coli class Ia ribonucleotide reductase (RNR) causes sensitivity to reactive oxygen species. Plating efficiency of Rm1021 (squares), $S m \mathrm{NrdJ}^{+}$(circles), and $S m \mathrm{NrdAB}^{+}$ (triangles) on Luria Bertani supplemented with $2.5 \mathrm{mM}$ magnesium sulfate and $2.5 \mathrm{mM}$ calcium chloride plates containing $\mathbf{A}$, hydrogen peroxide, $\mathbf{B}$, cumene hydroperoxide, or $\mathbf{C}$, menadione is expressed as a percentage of the colony number in the absence of treatment. Each point represents the mean of three independent cultures, and error bars represent standard error.
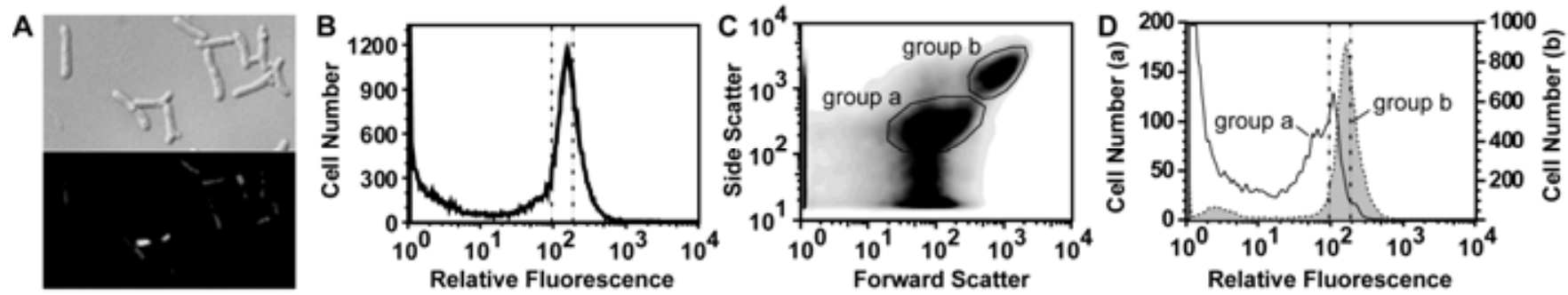

Fig. 5. Cellular morphology and DNA content of $S m \mathrm{NrdAB}^{+}$treated with hydroxyurea (HU). A, Free-living $\operatorname{SmNrdAB}{ }^{+}$treated with $1 \mathrm{mM} \mathrm{HU}$ was analyzed by microscopy and by $\mathbf{B}$ through $\mathbf{D}$, flow cytometry. The two populations shown in $\mathbf{C}$ are represented in (D) (note the fivefold difference in the scale of the $y$ axis). 
RNR activity is presumably required at several stages during infection of the nodule when DNA synthesis or repair occurs. DNA synthesis occurs when certain populations of cells proliferate in the infection thread (Gage 2002) and later when cells undergo endoreduplication during bacteroid differentiation (Mergaert et al. 2006; Paau and Cowles 1978b; Paau et al. 1979). The presence of DNA strand breaks and the localization of double-strand break DNA repair proteins suggest that DNA repair is common in bacteroids (Kobayashi et al. 2001, 2008). Our observation that numerous bacteria are present in infection threads containing $\mathrm{SmNrdAB}^{+}$indicates that DNA synthesis and cell division occur relatively normally in infection threads. However, the presence of elongated cells in these infection threads indicates that the cells could be experiencing a degree of DNA stress similar to the effect of treatment of $\mathrm{SmNrdAB}^{+}$ with HU or exposure of wild-type S. meliloti to DNA-damaging agents (Latch and Margolin 1997). This phenotype suggests that the class Ia RNR may progressively lose activity in the infection thread, causing the dNTP reserves of the bacterial cells to be depleted. Bacterial cell lysis may occur upon release from the infection thread, as the bacteria attempt to initiate genomic endoreduplication with very limited dNTP pools. Production of ROS and RNS is a common antimicrobial strategy in eukaryotic cells. For example, mammalian leukocytes localize ROS, RNS, and other antimicrobial compounds to phagosomes in order to kill pathogens that have been engulfed (Fialkow et al. 2007). Similarly, plants produce ROS and RNS as part of the defense response against pathogens (Apel and Hirt 2004). A common survival mechanism employed by both pathogenic and mutualistic bacteria involves destroying ROS by increasing the production of catalases and superoxide dismutases (Day et al. 2000; De Groote et al. 1997; Lindgren et al. 2007). Despite the importance of catalase activity for symbiosis with alfalfa (Jamet et al. 2003), destroying ROS and RNS entirely would not be a suitable mechanism for $S$. meliloti to overcome the oxidative stress encountered in the plant, because ROS and RNS are critical for both signaling and structural maintenance of the infection thread (Jamet et al. 2007; Peleg-Grossman et al. 2007). Indeed, overexpression of catalase has been shown to cause infection-thread cell-wall anomalies (Jamet et al. 2007). Consistent with a critical role of ROS and RNS in nodule development, we have observed that treatment of roots with compounds that quench nitric oxide or prevent its production inhibits nodule formation (not shown). A different strategy for survival in the presence of ROS and RNS is to decrease the permeability of the cell to small molecules (PalazzoloBallance et al. 2008). S. meliloti employs this strategy by increasing the production of exopolysaccharide in the infection thread, which is moderately protective against oxidative stress; in addition exopolysaccharide acts by modulating the plant's defense response (Davies and Walker 2007; Jones et al. 2008; Nogales et al. 2006). An additional mechanism of avoiding killing by ROS and RNS is the production of proteins that are less vulnerable to inactivation by ROS and RNS. S. meliloti apparently employs this strategy by expression of the class II RNR.

Many pathogenic bacteria reside within a eukaryotic host cytoplasm for months or even years. Several mammalian pathogens, including those of the genera Chlamydia, Mycobacterium, Salmonella, Rickettsia, Burkholderia, and Brucella, are engulfed by the mammalian host cell and survive a defense response in which ROS and RNS are produced by the host (Fang 2004; Roop et al. 2009; Walker et al. 2003). Therefore, each of these bacteria must have mechanisms to survive in an environment that is able to eliminate most other bacteria. Some intracellular pathogens, including Mycobacterium, Brucella, and Burkholderia, possess both a class I and class II
RNR (Dawes et al. 2003; Lundin et al. 2009). Interestingly, the class Ic RNR, a ROS- and RNS-resistant variant of the class Ia RNR of E. coli, was discovered recently in Chlamydia trachomatis and is thought to facilitate survival in the host cytoplasm (Hogbom et al. 2004; Jiang et al. 2008). Further studies on the ROS-resistant RNR of symbiotic and pathogenic bacteria may define the roles of these enzymes in bacterial survival within the host and may lead to the discovery of new methods of microbial control.

\section{MATERIALS AND METHODS}

Bacterial strains, plasmids, and growth conditions.

All S. meliloti strains are derivatives of wild-type strain Rm1021 (Meade et al. 1982). S. meliloti strains were grown at $30^{\circ} \mathrm{C}$ in LBMC (Luria Bertani supplemented with $2.5 \mathrm{mM}$ magnesium sulfate and $2.5 \mathrm{mM}$ calcium chloride) or M9 sucrose medium supplemented with $10 \mu \mathrm{g}$ of biotin per liter and $10 \mu \mathrm{M}$ cobalt chloride (Maniatis et al. 1982). E. coli strains used for genetic manipulations were grown at $37^{\circ} \mathrm{C}$ in $\mathrm{LB}$. When necessary, media were supplemented with antibiotics at the following concentrations (mg/liter): streptomycin, 500; spectinomycin, 100; kanamycin, 25; tetracycline, 5; and neomycin, 200. Where indicated, HU (1 mM) or methionine $(0.1$ $\mathrm{mg} / \mathrm{ml}$ ) was added to media. Sensitivity to hydrogen peroxide, cumene hydroperoxide, and menadione was assayed on LBMC plates buffered with $10 \mathrm{mM}$ HEPES, pH 7.4.

\section{Genetic and molecular techniques.}

The plasmid expressing E. coli metE was constructed by amplifying met $E$ from $E$. coli MG1655 genomic DNA by polymerase chain reaction (PCR) with primers 5'-GTCTCGAGTT ACATATAATTAGAGGAAG and 5'-GTGGTACCCCACCCG GTTTGGATTTTACC and cloning into pMS03 (Keating et al. 2002) at the XhoI and KpnI restriction sites. The plasmid expressing A. tumefaciens nrdJ was constructed similarly by amplifying from A. tumefaciens C28 genomic DNA with the primers 5'-GTCTCGAGTGGACGAGGACACGAAACCATG and 5'-GTGGTACCTCAAGACGAACCGCTCGTCGCA. Ligation mixtures were introduced into $E$. coli $\mathrm{DH} 5 \alpha$ by transformation. The plasmid expressing $E$. coli $n r d A$ and $n r d B$ was constructed by amplifying the $n r d A$ and $n r d B$ genes from $E$. coli MG1655 genomic DNA with primers 5'-GCCTCGAGAC AGGTACGACATACATGAATC and 5'-GTCTCGAGCCATC AGAGCTCCAAGTTACTC and cloning into pMS03 at the XhoI site. The orientation of the insert in the resulting plasmids containing $n r d A B$ was determined by digesting with KpnI. All plasmids were sequenced and introduced into $S$. meliloti by triparental mating (Leigh et al. 1985).

To construct a deletion in the chromosomal copy of $n r d J$, a 790-bp fragment including the first $61 \mathrm{bp}$ of the $n r d J$ coding sequence and the region upstream of $n r d J$ was amplified by PCR with primers 5'-TCATAAGCTTAGATTGCAGTCCTCC GATACGT and 5'-AATGCATGCGGAACTCAATCTCGGCA TAG. A 730-bp fragment including the last $107 \mathrm{bp}$ of $n r d J$ and the region downstream of $n r d J$ was amplified with primers $5^{\prime}-$ AATGCATHGAGGGCTATACCGGCAACA and 5'-AATGGA TCCCTGCCTTCGAATATGAGGGCT. Each PCR product was ligated into pCR2.1-TOPO using the TOPO-TA cloning kit (Invitrogen, San Diego, CA, U.S.A.). The 5' fragment was digested with HindIII and SphI, the $3^{\prime}$ fragment was digested with SphI and BamHI, and both were purified by gel extraction (Qiagen, Basel, Switzerland). The two products were ligated in tandem into pK18 mob sacB (Schafer et al. 1994) that was digested with HindIII and BamHI. The resulting deletion construct was introduced into $S$. meliloti harboring a plasmid expressing A. tumefaciens $n r d J$ or E. coli $n r d A$ and $n r d B$. Neo- 
mycin-resistant exconjugants were grown on tryptone-yeast plates containing $10 \%$ sucrose to select for a second crossover (Rosado and Gage 2003; Schafer et al. 1994). Neomycin-sensitive colonies were screened by PCR for loss of the $n r d J$ gene.

\section{Plant nodulation, acetylene reduction, and staining for GUS activity.}

Seedlings of Medicago sativa cv. Iroquois were inoculated with S. meliloti strains on Jensen agar (Leigh et al. 1985). All experiments with whole plants and nodules were performed four weeks after inoculation with $S$. meliloti. Acetylene reduction assays on whole plants were performed as described (Oke and Long 1999a). Whole plants were imaged with an HP Photosmart scanner. Whole nodules containing bacteria harboring the gus-expressing plasmid pTH1227 (Cheng et al. 2007) were stained for GUS activity as described (Kobayashi et al. 2008) and were sectioned by hand.

\section{Extraction of bacterial cells from nodules.}

Nodules from nine plants were surface-sterilized for $1 \mathrm{~min}$ in $100 \%$ bleach and were washed three times in water. Nodules were crushed in MMS medium (Finan et al. 1991), and the liquid containing bacteroids was removed with a pipette. Samples were centrifuged twice at 2,200 $\times g$ for 5 min and were resuspended in MMS medium. For flow cytometry, small particles were removed by passing through a $0.2-\mu \mathrm{m}$ filter (Millipore, Bedford, MA, U.S.A.) prior to analysis.

\section{Microscopy.}

Whole nodules excised from roots and hand-sectioned nodules stained for GUS activity were examined with a Nikon Eclipse microscope equipped with a CCD camera. Free-living bacteria grown in M9 and bacterial cells extracted from nodules were stained with DAPI (Molecular Probes, Eugene, OR, U.S.A.) and were visualized by microscopy on slides prepared as described (Lemon and Grossman 1998). Images were processed with Adobe Photoshop. Tissue preparation, sectioning, staining, and electron microscopy were performed as described (Hirsch et al. 1983).

\section{Flow cytometry.}

Samples of free-living bacteria and nodule extracts were fixed by mixing with ethanol to a final concentration of $85 \%$. Following overnight incubation at $4^{\circ} \mathrm{C}$, cells were harvested by centrifugation at $4,000 \times g$ for $4 \mathrm{~min}$ and were resuspended in 1 volume $50 \mathrm{mM}$ sodium citrate buffer containing $3.3 \mathrm{mg}$ of RNase per milliliter. Samples were incubated overnight at $50^{\circ} \mathrm{C}$ and were passed through a cell strainer cap (BD Falcon, BD Biosciences, San Jose, CA, U.S.A.) to remove large particles. The samples were then stained with the nucleic acid-binding dye Sytox Green (Molecular Probes) at a final concentration of $0.83 \mu \mathrm{M}$ and were analyzed on a Becton Dickinson FACScan flow cytometer. Data were analyzed with FlowJo software (Tree Star, Inc., Ashland, OR, U.S.A.).

\section{ACKNOWLEDGMENTS}

We are indebted to N. Watson and the W. M. Keck Foundation Biological Imaging Facility for preparing nodule sections and performing electron microscopy; M. L. Pardue, M. B. Berkmen, and A. Grossman for assistance with microscopy; and G. Paradis, M. Griffin, A. Fan, C. Peterson, and the MIT Flow Cytometry Core Facility for assistance with flow cytometry. We thank A. Hirsch for her insights about the electron micrographs, K. Jones for critical reading of the manuscript, and members of the Walker laboratory for helpful discussions. This work was funded by NIH grant GM31010 to G. C. Walker and NIH grant K99 GM083343 and a postdoctoral fellowship from the Jane Coffin Childs Memorial Fund for Medical Research to M. E. Taga. G. C. Walker is an American Cancer Society Research Professor.

\section{LITERATURE CITED}

Abbas, B. A., Vineetha, K. E., Prasad, C. K., Vij, N., Hassani, R., and Randhawa, G. S. 2002. Symbiotic characteristics of cysteine and methionine auxotrophs of Sinorhizobium meliloti. Indian J. Exp. Biol. 40:1121-1130.

Ampe, F., Kiss, E., Sabourdy, F., and Batut, J.. 2003. Transcriptome analysis of Sinorhizobium meliloti during symbiosis. Genome Biol. 4:R15.

Apel, K., and Hirt, H.. 2004. Reactive oxygen species: Metabolism, oxidative stress, and signal transduction. Annu. Rev. Plant Biol. 55:373-399.

Banerjee, R., and Chowdhury, S. 1999. Methylmalonyl-CoA mutase. Pages 707-729 in: Chemistry and Biochemistry of $B_{12}$. R. Banerjee, ed. John Wiley \& Sons, Inc., New York.

Barra, L., Fontenelle, C., Ermel, G., Trautwetter, A., Walker, G. C., and Blanco, C. 2006. Interrelations between glycine betaine catabolism and methionine biosynthesis in Sinorhizobium meliloti strain 102F34. J. Bacteriol. 188:7195-7204.

Battistoni, F., Platero, R., Noya, F., and Fabiano, E. 2002. Intracellular Fe content influences nodulation competitiveness of Sinohizobium meliloti strains as inocula of alfalfa. Soil Biol. Biochem. 34:593-597.

Baudouin, E., Pieuchot, L., Engler, G., Pauly, N., and Puppo, A. 2006. Nitric oxide is formed in Medicago truncatula-Sinorhizobium meliloti functional nodules. Mol. Plant-Microbe Interact. 19:970-975.

Buckel, W., Kratky, C., and Golding, B. T. 2005. Stabilisation of methylene radicals by cob(II)alamin in coenzyme $\mathrm{B}_{12}$ dependent mutases. Chemistry 12:352-362.

Campbell, G. R., Reuhs, B. L., and Walker, G. C. 2002. Chronic intracellular infection of alfalfa nodules by Sinorhizobium meliloti requires correct lipopolysaccharide core. Proc. Natl. Acad. Sci. U.S.A. 99:3938-3943.

Campbell G. R. O., Taga, M. E., Mistry, K., Lloret, J., Anderson, P., Roth, J. R., and Walker, G. C. 2006. Sinorhizobium meliloti bluB is necessary for production of 5,6-dimethylbenzimidazole, the lower ligand of $\mathrm{B}_{12}$. Proc. Natl. Acad. Sci. U.S.A. 103:4634-4639.

Carlson, J., Fuchs, J. A., and Messing, J. 1984. Primary structure of the Escherichia coli ribonucleoside diphosphate reductase operon. Proc. Natl. Acad. Sci. U.S.A. 81:4294-4297.

Charles, T. C., and Aneja, P. 1999. Methylmalonyl-CoA mutase encoding gene of Sinorhizobium meliloti. Gene 226:121-127.

Cheng, J., Sibley, C. D., Zaheer, R., and Finan, T. M. 2007. A Sinorhizobium meliloti minE mutant has an altered morphology and exhibits defects in legume symbiosis. Microbiology 153:375-387.

Chu, J., Shoeman, R., Hart, J., Coleman, T., Mazaitis, A., Kelker, N., Brot, N., and Weissbach, H. 1985. Cloning and expression of the metE gene in Escherichia coli. Arch. Biochem. Biophys. 239:467-474.

Cowles, J. R., and Evans, H. J. 1968. Some properties of the ribonucleotide reductase from Rhizobium meliloti. Arch. Biochem. Biophys. 127:770-778.

Davies, B. W., and Walker, G. C. 2007. Disruption of sitA compromises Sinorhizobium meliloti for manganese uptake required for protection against oxidative stress. J. Bacteriol. 189:2101-2109.

Davies, B. W., Kohanski, M. A., Simmons, L. A., Winkler, J. A., Collins, J. J., and Walker, G. C. 2009. Hydroxyurea induces hydroxyl radicalmediated cell death in Escherichia coli. Mol. Cell 36:845-860.

Dawes, S. S., Warner, D. F., Tsenova, L., Timm, J., McKinney, J, D., Kaplan, G., Rubin, H., and Mizrahi, V. 2003. Ribonucleotide reduction in Mycobacterium tuberculosis: Function and expression of genes encoding class $\mathrm{Ib}$ and class II ribonucleotide reductases. Infect. Immun. 71:6124-6131.

Day, W A., Jr., Sajecki, J. L., Pitts, T. M., and Joens, L. A. 2000. Role of catalase in Campylobacter jejuni intracellular survival. Infect. Immun. 68:6337-6345

De Groote, M. A., Ochsner, U. A., Shiloh, M. U., Nathan, C., McCord, J. M., Dinauer, M. C., Libby, S. J., Vazquez-Torres, A., Xu, Y., and Fang, F. C. 1997. Periplasmic superoxide dismutase protects Salmonella from products of phagocyte NADPH-oxidase and nitric oxide synthase. Proc. Natl. Acad. Sci. U.S.A. 94:13997-14001

Dehal, P. S., Joachimiak, M. P., Price, M. N., Bates, J. T., Baumohl, J. K., Chivian, D., Friedland, G. D., Huang, K. H., Keller, K., Novichkov, P. S., Dubchak, I. L., Alm, E. J., and Arkin, A. P. 2010. MicrobesOnline: An integrated portal for comparative and functional genomics. Nucleic Acids Res. 38:D396-400.

Djordjevic, M. A. 2004. Sinorhizobium meliloti metabolism in the root nodule: A proteomic perspective. Proteomics 4:1859-1872.

Elford, H. L. 1968. Effect of hydroxyurea on ribonucleotide reductase. Biochem. Biophys. Res. Commun. 33:129-135.

Evans, H. J., and Kliewer, M. 1964. Vitamin $B_{12}$ compounds in relation to the requirement of cobalt for higher plants and nitrogen-fixing organisms. Ann. NY Acad. Sci. 112:735-755.

Fang, F. C. 2004. Antimicrobial reactive oxygen and nitrogen species: 
Concepts and controversies. Nat. Rev. Microbiol. 2:820-832.

Fialkow, L., Wang, Y., and Downey, G. P. 2007. Reactive oxygen and nitrogen species as signaling molecules regulating neutrophil function. Free Radic. Biol. Med. 42:153-164.

Finan, T. M., McWhinnie, E., Driscoll, B., and Watson, R. J. 1991. Complex Symbiotic Phenotypes Result from Gluconeogenic Mutations in Rhizobium meliloti. Mol. Plant-Microbe Interact. 4:386-392.

Fontecave, M. 1998. Ribonucleotide reductases and radical reactions. Cell Mol. Life Sci. 54:684-695.

Fontecave, M., and Gerez, C. 2002. Tyrosyl radicals and ribonucleotide reductase. Methods Enzymol. 348:21-30.

Gage, D. J. 2002. Analysis of infection thread development using Gfpand DsRed-expressing Sinorhizobium meliloti. J. Bacteriol. 184:70427046.

Gage, D. J., and Margolin, W. 2000. Hanging by a thread: Invasion of legume plants by rhizobia. Curr. Opin. Microbiol. 3:613-617.

Garriga, X., Eliasson, R., Torrents, E., Jordan, A., Barbé, J., Gibert, I., and Reichard, P. 1996. $n r d D$ and $n r d G$ genes are essential for strict anaerobic growth of Escherichia coli. Biochem. Biophys. Res. Commun. 229:189-192.

Gibson, K. E., Kobayashi, H., and Walker, G. C. 2008. Molecular determinants of a symbiotic chronic infection. Annu. Rev. Genet. 42:413-441.

Glazebrook, J., Ichige, A., and Walker, G. C. 1993. A Rhizobium meliloti homolog of the Escherichia coli peptide-antibiotic transport protein SbmA is essential for bacteroid development. Genes Dev. 7:1485-1497.

Gonzalez, J. C., Banerjee, R. V., Huang, S., Sumner, J. S., and Matthews, R. G. 1992. Comparison of cobalamin-independent and cobalamindependent methionine synthases from Escherichia coli: Two solutions to the same chemical problem. Biochemistry 31:6045-6056.

Hirsch, A. M., Bang, M., and Ausubel, F. M. 1983. Ultrastructural analysis of ineffective alfalfa nodules formed by nif::Tn5 mutants of Rhizobium meliloti. J. Bacteriol. 155:367-380.

Hogbom, M., Stenmark, P., Voevodskaya, N., McClarty, G., Graslund, A., and Nordlund, P. 2004. The radical site in chlamydial ribonucleotide reductase defines a new R2 subclass. Science 305:245-248.

Hondorp, E. R., and Matthews, R. G. 2004. Oxidative stress inactivates cobalamin-independent methionine synthase (MetE) in Escherichia coli. PLoS Biol 2:e336. Published online.

Jamet, A., Sigaud, S., Van de Sype, G., Puppo, A., and Herouart, D. 2003. Expression of the bacterial catalase genes during Sinorhizobium meliloti-Medicago sativa symbiosis and their crucial role during the infection process. Mol. Plant-Microbe Interact. 16:217-225.

Jamet, A., Mandon, K., Puppo, A., and Herouart, D. 2007. $\mathrm{H}_{2} \mathrm{O}_{2}$ is required for optimal establishment of the Medicago sativa/Sinorhizobium meliloti symbiosis. J. Bacteriol. 189:8741-8745.

Jiang, W., Xie, J., Norgaard, H., Bollinger, J. M., Jr., and Krebs, C. 2008. Rapid and quantitative activation of Chlamydia trachomatis ribonucleotide reductase by hydrogen peroxide. Biochemistry 47:4477-4483.

Jones, K. M., Kobayashi, H., Davies, B. W., Taga, M. E., and Walker, G. C. 2007. How rhizobial symbionts invade plants: The SinorhizobiumMedicago model. Nat. Rev. Microbiol. 5:619-633.

Jones, K. M., Sharopova, N., Lohar, D. P., Zhang, J. Q., VandenBosch, K. A., and Walker, G. C. 2008. Differential response of the plant Medicago truncatula to its symbiont Sinorhizobium meliloti or an exopolysaccharide-deficient mutant. Proc. Natl. Acad. Sci. U.S.A. 105:704-709.

Keating, D. H., Willits, M. G., and Long, S. R. 2002. A Sinorhizobium meliloti lipopolysaccharide mutant altered in cell surface sulfation. J. Bacteriol. 184:6681-6689.

Kobayashi, H., Sunako, M., Hayashi, M., and Murooka, Y. 2001. DNA synthesis and fragmentation in bacteroids during Astragalus sinicus root nodule development. Biosci. Biotechnol. Biochem. 65:510-515.

Kobayashi, H., Simmons, L. A., Yuan, D. S., Broughton, W. J., and Walker, G. C. 2008. Multiple Ku orthologues mediate DNA non-homologous end-joining in the free-living form and during chronic infection of Sinorhizobium meliloti. Mol. Microbiol. 67:350-363.

Kolberg, M., Strand, K. R., Graff, P., and Andersson, K. K. 2004. Structure, function, and mechanism of ribonucleotide reductases. Biochim. Biophys. Acta 1699:1-34.

Latch, J. N., and Margolin, W. 1997. Generation of buds, swellings, and branches instead of filaments after blocking the cell cycle of Rhizobium meliloti. J. Bacteriol. 179:2373-2381.

Leigh, J. A., Signer, E. R., and Walker, G. C. 1985. Exopolysaccharidedeficient mutants of Rhizobium meliloti that form ineffective nodules. Proc. Natl. Acad. Sci. U.S.A. 82:6231-6235.

Lemon, K. P., and Grossman, A. D. 1998. Localization of bacterial DNA polymerase: Evidence for a factory model of replication. Science 282:1516-1519.

Lindgren, H., Shen, H., Zingmark, C., Golovliov, I., Conlan, W., and Sjostedt, A. 2007. Resistance of Francisella tularensis strains against reactive nitrogen and oxygen species with special reference to the role of KatG. Infect. Immun. 75:1303-1309.

Lodwig, E. M., and Poole, P. S. 2003. Metabolism of Rhizobium bacteroids. Crit. Rev. Plant Sci. 22:37-78.

Lundin, D., Torrents, E., Poole, A. M., and Sjoberg, B. M. 2009. RNRdb, a curated database of the universal enzyme family ribonucleotide reductase, reveals a high level of misannotation in sequences deposited to Genbank. BMC Genomics 10:589.

Maniatis, T., Fritsch, E. F., and Sambrook, J. 1982. Molecular Cloning: A Laboratory Manual. Cold Spring Harbor Laboratory Publications, Cold Spring Harbor, NY, U.S.A.

Matthews, R. G. 1999. Cobalamin-dependent methionine synthase. Pages 681-706 in: Chemistry and Biochemistry of $\mathrm{B}_{12}$. R. Banerjee, ed. John Wiley \& Sons, Inc., New York.

Maunoury, N., Redondo-Nieto, M., Bourcy, M., Van de Velde, W., Alunni, B., Laporte, P., Durand, P., Agier, N., Marisa, L., Vaubert, D., Delacroix, H., Duc, G., Ratet, P., Aggerbeck, L., Kondorosi, E., and Mergaert, P. 2010. Differentiation of symbiotic cells and endosymbionts in Medicago truncatula nodulation are coupled to two transcriptomeswitches. PLoS One 5:e9519. Published online.

McCutcheon, J. P., McDonald, B. R., and Moran, N. A. 2009. Convergent evolution of metabolic roles in bacterial co-symbionts of insects. Proc. Natl. Acad. Sci. U.S.A.

Meade, H. M., Long, S. R., Ruvkun, G. B., Brown, S. E., and Ausubel, F. M. 1982. Physical and genetic characterization of symbiotic and auxotrophic mutants of Rhizobium meliloti induced by transposon $\mathrm{Tn} 5$ mutagenesis. J. Bacteriol. 149:114-122.

Mergaert, P., Uchiumi, T., Alunni, B., Evanno, G., Cheron, A., Catrice, O Mausset, A.-E., Barloy-Hubler, F., Galibert, F., Kondorosi, A.,and Kondorosi, E. 2006. Eukaryotic control on bacterial cell cycle and differentiation in the Rhizobium-legume symbiosis. Proc. Natl. Acad. Sci. U.S.A. 103:5230-5235.

Miller, R. W., McRae, D. G., Al-Jobore, A., and Berndt, W. B. 1988. Respiration supported nitrogenase activity of isolated Rhizobium meliloti bacteroids. J. Cell Biochem. 38:35-49.

Nogales, J., Munoz, S., Olivares, J., and Sanjuan, J. 2006. Sinorhizobium meliloti genes involved in tolerance to the antimicrobial peptide protamine. FEMS (Fed. Eur. Microbiol. Soc.) Microbiol. Lett. 264:160-167

Oke, V., and Long, S. R. 1999a. Bacterial genes induced within the nodule during the Rhizobium-legume symbiosis. Mol. Microbiol. 32:837-849.

Oke, V., and Long, S. R. 1999b. Bacteroid formation in the Rhizobium-legume symbiosis. Curr. Opin. Microbiol. 2:641-646.

Paau, A. S., and Cowles, J. R. 1978a. Development of bacteroids in alfalfa (Medicago sativa) nodules. Plant Physiol. 62:526-530.

Paau, A. S., and Cowles, J. R. 1978b. Studies on bacteroid size and nucleic acid content of alfalfa bacteroids fractionated by velocity sedimentation. Can. J. Microbiol. 24:1283-1287.

Paau, A. S., Oro, J., and Cowles, J. R. 1979. DNA content of free living rhizobia and bacteroids of various Rhizobium-legume associations. Plant Physiol. 63:402-405.

Palazzolo-Balance, A. M., Reniere, M. L., Braughton, K. R., Sturdevant, D. E., Otto, M., Kreiswirth, B. N., Skaar, E. P., and DeLeo,, F. R. 2008. Neutrophil microbicides induce a pathogen survival response in community-associated methicillin-resistant Staphylococcus aureus. J. Immunol. 180:500-509.

Peleg-Grossman, S., Volpin, H., and Levine, A. 2007. Root hair curling and Rhizobium infection in Medicago truncatula are mediated by phosphatidylinositide-regulated endocytosis and reactive oxygen species. J. Exp. Bot. 58:1637-1649.

Raux, E., Schubert, H. L., and Warren, M. J. 2000. Biosynthesis of cobalamin (vitamin $\mathrm{B}_{12}$ ): A bacterial conundrum. Cell Mol. Life Sci. 57:18801893

Rodionov, D. A., Vitreschak, A. G., Mironov, A. A., and Gelfand, M. S. 2003. Comparative genomics of the vitamin $B_{12}$ metabolism and regulation in prokaryotes. J. Biol. Chem. 278:41148-41159.

Roop, R. M., 2nd, Gaines, J. M., Anderson, E. S., Caswell, C. C., and Martin, D. W. 2009. Survival of the fittest: How Brucella strains adapt to their intracellular niche in the host. Med. Microbiol. Immunol. 198:221-238

Rosado, M., and Gage, D. J. 2003. Transcriptional control of a rRNA promoter of the nodulating symbiont Sinorhizobium meliloti. FEMS (Fed. Eur. Microbiol. Soc.) Microbiol Lett 226:15-22.

Roth, J. R., Lawrence, J. G., and Bobik, T. A. 1996. Cobalamin (coenzyme $\mathrm{B}_{12}$ ): Synthesis and biological significance. Annu. Rev. Microbiol. 50:137-181.

Rubio, M. C., James, E. K., Clemente, M. R., Bucciarelli, B., Fedorova, M., Vance, C. P., and Becana, M. 2004. Localization of superoxide dismutases and hydrogen peroxide in legume root nodules. Mol. Plant-Microbe Interact. 17:1294-1305. 
Ryzhkova, E. P. 2003. Multiple functions of corrinoids in prokaryote biology. Appl. Biochem. Microbiol. 39:133-159.

Santos, R., Herouart, D., Puppo, A., and Touati, D. 2000. Critical protective role of bacterial superoxide dismutase in rhizobium-legume symbiosis. Mol. Microbiol. 38:750-759.

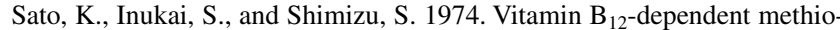
nine synthesis in Rhizobium meliloti. Biochem. Biophys. Res. Commun. 60:723-728.

Schafer, A., Tauch, A., Jager, W., Kalinowski, J., Thierbach, G., and Puhler, A. 1994. Small mobilizable multi-purpose cloning vectors derived from the Escherichia coli plasmids pK18 and pK19: Selection of defined deletions in the chromosome of Corynebacterium glutamicum. Gene 145:69-73.
Taga, M. E., Larsen, N. A., Howard-Jones, A. R., Walsh, C. T., and Walker, G. C. 2007. BluB cannibalizes flavin to form the lower ligand of vitamin $B_{12}$. Nature 446:449-453

Walker, D. H., Valbuena, G. A., and Olano, J. P. 2003. Pathogenic mechanisms of diseases caused by Rickettsia. Ann. NY Acad. Sci 990:1-11.

Wang, D., Griffitts, J., Starker, C., Fedorova, E., Limpens, E., Ivanov, S., Bisseling, T., and Long, S. 2010. A nodule-specific protein secretory pathway required for nitrogen-fixing symbiosis. Science 327:11261129

Witty, J. F., Skot, L., and Revsbech, N. P. 1987. Direct evidence for changes in the resistance of legume root nodules to $\mathrm{O} 2$ diffusion. J. Exp. Bot. 38:1129-1140. 